\title{
A Lexicalist Account of Icelandic Case Marking
}

\author{
Gosse Bouma \\ Computational Linguistics Department \\ University of Groningen, P.O. box 716 \\ NL-9700 AS Groningen, The Netherlands \\ email: gosseqlet.rug.nl
}

\begin{abstract}
Recent theoretical descriptions of the Icelandic case system distinguish between lexical and structural case. Lexical case is assigned in the lexicon, whereas structural case is assigned in syntax, under the provision that it does not override lexical case assignment. This analysis is problematic for grammatical theories such as Categorial Unification Grammar (CUG) and Headdriven Phrase Structure Grammar (HPSG) as the introducion of a syntactic case component is incompatible with the lexicalist ideology underlying these frameworks. Furthermore, the default character of syntactic case introduces a procedural aspect into the grammar which goes against the declarative spirit of unificationbased frameworks in general. In this paper, I propose an alternative analysis, formulated in terms of CUG, in which all case constraints are expressed lexically and in which default reasoning is restricted to nonmonotonic inheritance of lexical information only.
\end{abstract}

\section{Introduction: Case Marking and Defaults}

The Icelandic case marking system ${ }^{1}$ has often been taken as evidence for a distinction between structural (or regular or default) and lexical (irregular, quirky) case marking. This distinction is introduced to explain the following two facts. First, most verbs select nominative case marked subjects (1), but a number of verbs select accusative, genitive or dative subjects (2)(4). Similarly, most transitive or ditransitive verbs select an accusative direct object (1), but some select a nominative, dative, or genitive (4)(6) object.

(1) Stúlkan(N) kyssti drengina(A) the-girls kissed the-boys

\footnotetext{
${ }^{1}$ See Andrews (1982) for an extensive overview.
}

(2) Drengina( $(A)$ vantar mat $(\Lambda)$ the-boys lacks food

(3) Verkjanna(G) gæatir ekki the-pain is-noticeable not

(4) Barninu(D) batnaði veikin(N) the-child recovered-from the-disease

(5) Ég hjálpadj honum(D)

I helped him

(6) Ég mun sakna hans(G) I will miss him

The fact that the vast majority of subjects and objects is nominative and accusative, respectively, is accounted for by assigning default status to these cases (that is, if nothing is said about the case of a subject or object, assume it must be nominative or accusative, respectively).

Second, passive sentences (7)-(8) and so-called 'rajsing' constructions (9)-(12) exhibit a distinction between regular and irregular case marked NPs. In transformational terms, the case of regular case marked NPs corresponds with their surface position ((7), (9), and (11)), whereas the case of irregular case marked NPs corresponds to their underlying position $((8),(10)$, and (12)). (In these examples, $t_{C}$ represents a lexically case marked NP-trace and $t$ a trace which has not been assigned case (assuming that structural case is only assigned to surface NP positions)).

(7) Drengirnir(N) voru kysstir $t$ the-boys were kissed

(8) Honum(D) var hjálpað $t_{D}$ him was helped

(9) $\operatorname{Hann}(N)$ viròist [t elska hana] he seems to-love her

(10) Hana(A) viroist [ $t_{A}$ vanta peninga] her seems to-lack money 
(11) Ég taldi Guorúnu(A) $[t$ sakna

$I$ believed Gudrun to-miss

Haraldar]

IIarald

(12) Hann telur barninu(I) $)$ ( $t_{D}$ hafa

he believes the-cild to-have

batnad veikin ]

recovered-from the-disease

Preservation of irregular case is particularly striking is a sentence such as (13). Although, normally, a verb which selects an accusative object always selects a nominative subject when passivized, this is not so in (13), where a raising to object verb has been passived. 'The lexical case assigned by the embedded verb vanta is preserved even if raising to object and subsequent passivization takes place.

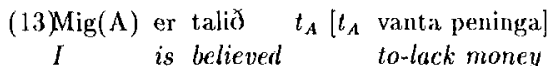

The interaction of case assignment, raising, and passivization is summarized in the table below (where $\downarrow$ and $\uparrow$ refer to the underlying and surface NP position, respectively). 'The distinction between structural and lexical accusative in passives is needed to account for a sentence such as (13). Transitive verbs with nominative objects do not passivize (Yip et al., 1987, p. 225).

\begin{tabular}{|l|l|ll|}
\hline Rai-to-S & Rai-to-O & \multicolumn{1}{|c|}{ Passive } \\
\hline 1 Sub $\uparrow S u b$ & $\downarrow S u b \uparrow O b j$ & $1 O b j$ & $\uparrow S u b$ \\
\hline Nom Nom & Nom Acc & Acc(s.) & NOM \\
Acc Acc & Acc Acc & Acc(1.) & Acc \\
Dat Dat & Dat Dat & Dat & Dat \\
Gen Gen & Gen Gen & Gen & Gen \\
\hline
\end{tabular}

Table 1: Icelandic Case Patterns

All previous accounts of these facts ${ }^{2}$ have adopted the following two assumptions:

- Lexical case is assigned in the lexicon (that is, before the lexical and syntactic processes responsible for passive formation and raising have applied) and structural case is assigned in syntax (after all other syntactic processing has been completed).

- Structural case assignment is a default process which can never override lexical case assignments.

\footnotetext{
${ }^{2}$ Except Sag et al. (to appear), whose analysis is in many respects similar to the one developed below.
}

Andrews' (1982, p. 485) LFG-based account, for instance, assumes two default conventions, applicable to functional structures (that is, after syutactic processing has been completed). First, if the subject is uninarked for case, (direct and indirect) objects are accusative by default (i.e. only if they are not lexically case marked), and, second, an argument must be nominative if no other case constraint has been imposed upon it. 'The application of the first convention must precede that of the second. 'Zaenen et al. (1985, p. 466) adopt a default case marking convention which appears to be restricted to the lexicon and which assigns nominative case to the highest available grammatical function (i.e. a grammatical function which is present in the argument (or thematic) structure of a verb and which has not been assigned lexical case), and accusative to the next highest available grammatical function. Zaenen at al. concentrate primarily on passives and do not present an explicit account of raising constructions. Yip ct al. (1987), inspired by ideas from autosegmental phonology, propose a system in which a case tier [NOM ACC] is associated with verbal arguments in syntax in a left-to-right fashion, in such a way that nom is associated with the leftmost argument that has not been assigned lexical case and ACC is associated with the next available argument. Their account of raising to object assumes that case association is a cyclic rule and that syntactic (as opposed to lexical) case assignments may be overwritten by syntactic case assignments in higher cycles.

These proposals are problematic for standard unification-based formalisms of the PA'TR-II varicty (Shicber, 1986a). The default constraints for nominative and aecusative case marking must not apply if a lexical case constraint is present alrearly. 'This implies that the default constraints cannot be added to the syntactic rules or lexical entries which introduce subjects and objects, as this would make the constraints alsolute. Rather, syntactic default case marking principles would have to be added as a filter on syntactic structures or as seperate default rules (much like the syntactic feature specification defaults of GPSG) whose application must be intertwined with syntactic processing ${ }^{3}$. Admitting such extensions, however, is potentially damaging to the descriptive adequacy of

\footnotetext{
${ }^{3}$ Note that the defaults cannot be 'compiled away' in this case, as is proposed for the feature specification defaults of (iPSG in Shieber (1986b).
} 
unification-based formalisms, as the addition of syntactic filters adds a powerful and secmingly unrestricted level of description to the grammar formalism and the addition of syntactic defaults introduces a procedural aspect to syntactic descriptions which is absent in the standard formalism.

The proposals of Anelrews (1982) and Yip et al. (1987) are also a challongo for lexicalist theories such as IIPSG and CUG. The problem for lexicalist theories is that the default principles above must make use of information which is only available after a certain amount of syntactic processing has taken place. In raising to object constructions, for instance, the question whether the object must be assigned accusative case or not can only be answered after it is known whether the sub ject of the embedded $V P$ is assigned lexical case or not. These considerations have even been used (in Jacobson, 1990) as arguments against lexicalist accounts of case marking in general.

Below, I will demonstrate that the Icelandic lata can be accounted for declaratively and in a lexicalist fashion. In the next section, I introduce a fragment of CUG including raising verbs and passives. Next, the distinction between lexical and structural case is accounted for by assuming that case is encoded as a featurecomplex and by introducing a system for nonmonotonic inheritance of lexical information. In section 1 I show that this decomposed case system makes it possible to analyze the case patterns found in passive and raising constructions as a refection of a partial agreement relation. 'The final section compares the present proposal with recent work by Sag et al. (to appear).

\section{Categorial Unification Gram- mar}

In this section, I will present a brief outline of Categorial Unification Grammar (CUG), a unification-based version of Categorial Grammar (see, among others, Uszkoreit (1986), Karttunen (1989), Bouma (1988), and Zeevat (1988), for details). In particular, the treatment of raising verbs and passives will be adressed.

The categories of categorial grammar can be encoded as feature-structures nsing the feature CAT(EGORY) to represent basic categories and the features VAL(UE), ARG(UMENT) and DIR(FCTIONALITY) to represent complex cate- gories. The category $N P \backslash S$, for instance, is translated as:

(14) $\left[\begin{array}{lll}\text { val } & \text { lat } & \text { cat } \\ \text { dir } & \text { left } \\ \text { arg } & {[\text { cat }} & \text { np }] \\ \text { cat } & \text { - }\end{array}\right]$

The specification [CAT - ] is needed only to make complex categories non-unifiable with basic categories. I will omit this specification in the examples below. The template system in (15) defines the basic inventory of categories that is assumed in the sequel ${ }^{4}$.

$$
\begin{array}{llll}
N P & :(\langle c a t\rangle=n p) \\
S & :(\langle c a t\rangle=s) \\
V P & :(N P \backslash S & ) \\
T V P & :( & V P / N P & )
\end{array}
$$

I assume a categorial grammar which provides (at least) the following combinatory rules:

Right Application: $\alpha \beta, X \Rightarrow \alpha, X / Y \quad \beta, Y$

Left Application: $\beta \alpha, X \Rightarrow \beta, Y \quad \alpha, Y \backslash X$

Right Wrap: $\alpha_{1} \beta \alpha_{2}, X \Rightarrow \alpha_{1} \alpha_{2}, X / Y \quad \beta, Y$

These rules can be thought of as licencing certain operations on strings and feature structures. This is illustrated for leftward application in (16) below.

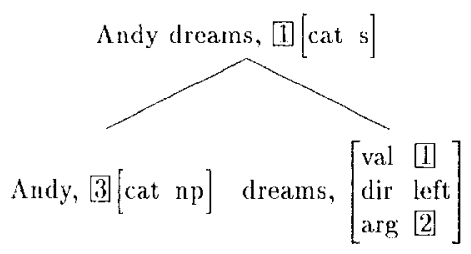

All combinatory rules unify the value of the functor danghter with the feature structure of the mother and unify the argument of the functor with the argument daughter.

Raising verbs subcategorize for a $\mathrm{VP}$-complement (i.e. a category $N P \backslash S$ ) the subject of which is controlled by an NP-argument of the raising verb. Following Bach (1979) I assume that the controller is always the so-called nextargument-in. 'That is, a 'raising to subject' verb such as seem receives the category $(N P \backslash S) / V P$,

\footnotetext{
${ }^{4} I$ use $X / Y$ and $Y \backslash X$ as shorthand for $\langle v a l\rangle=X \quad\langle$ val $\rangle=X$

$\langle$ dir $\rangle=r i g h t \quad$ and $\quad\langle d i r\rangle=r i g h t$

$\langle a r y\rangle=Y \quad\langle a r y\rangle=Y$
} 
whereas a 'raising to object' verb such as $e x$ pect is categorized as $(V P / N P) / V P$. This implies that such verbs combine with their object using right wrap ${ }^{5}$ :
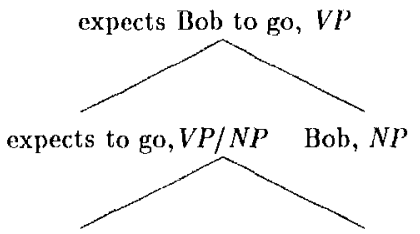

expects, $(V P / N P) / V P$ to go, $V P$

The semantic and syntactic implications of the relation between the controlling NP and the subject of the VP-complement can be implemented by making these two arguments reentrant. I will ignore this aspect of the analysis below (but see Pollard \& Sag (to appear) for an analysis which makes a similar assumption).

Passive auxiliaries subcategorize for a passive TVP (i.e. a category $V P / N P$ with passive morphology) and a subject NP (that is, I adopt a lexicalized version of the analysis in Bach (1980)). The fact that the subject is interpreted as the object of the TVP can again be implemented by making these two argument positions reentrant. Since raising to object verbs are functors which are reducible to 'I'VP', this analysis predicts that such verbs may be passivized:

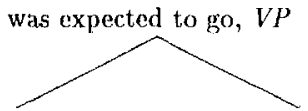

was, $V P / T V P$ expected to go, 'I' $V P$ '

\section{Distinguishing Lexical and Structural Case}

'The most important tool for expressing linguistic generalizations in unification-based formalisms is the template mechanism. In this section, I introduce the template system for case and show how nonmonotonic template inheritance can be used to account for the default character of structural case.

The distinction between lexical and structural case can be made explicit if case is encoded as

\footnotetext{
${ }^{5}$ The feature structures above encode only the directionality of functors, not their mode of combination (i.e. application or wrap). It is possible to add a feature which encodes this information explicitly.
}

a feature complex. That is, instead of using a single feature CASF, I will use three distinct features. The feature sThuC' distinguishes between structural and lexical case, and the features $\mathrm{I}, \mathrm{E} X$ and NOM distinguish between the various lexical cases and between nominative and accusative structural case, respectively. 'The data in section 1 show that genitive and dative case are always lexical (i.e. non-structural), that accusative may be lexical (if assigned to subjects) as well as structural (if assigned to objects), and that nominative is always structural. 'Therefore, I assume that the templates Nom, ACC, DAT, and GLN assign the values specified in table 2 to the features mentioned above. The

\begin{tabular}{|l|ccc|}
\hline & struct lex & nom \\
\hline NoM & + & & + \\
ACC & & acc & - \\
JAT & - & dat & \\
GeN & - & gen & \\
\hline
\end{tabular}

Table 2: Decomposing Case

fact that ACC is unspecified for sTrucr is important in the account of case preservation presented below. Note that these four template definitions denote incompatible feature structures and thus can be used to define the morphological case of NPs in lexical entries:

(19) Stúlkan :( NPNom $)$.
Drengina :

Intransitive and transitive verbs, are defined as follows (where +STRuct denotes a positive value for STRUCT):

$$
\begin{aligned}
& I V:\left(\begin{array}{l}
\left(N I^{\prime} N o m\right) \backslash S \\
T V:( \\
I V /(N P A c c+S t r u c t)
\end{array}\right) .
\end{aligned}
$$

Note that the fact that accusative acts as a structural case for objects has been added explicitly.

Both structural and lexical case assigning verbs are defined in terms of the templates in (20). For structural case assigning verbs only their category needs to be specified. The definitions of lexical case assigning verbs, on the other hand, will contain explicit case constraints. To avoid feature-clashes, I assume that these irregular verbs inherit nonmonotonically from the tem- 
plates above:

(21) kyssti : (TV

hjalpaời : ( TV

$$
\begin{gathered}
!\langle a r g\rangle=\text { Dat } \\
\text { vantar }:(T V) . \\
!(\text { val arg }\rangle=(\text { Acc }- \text { Struct })) .
\end{gathered}
$$

In these definitions, the '?'-prefix (comparable to the overwrite operator of PATR-II) indicates that the following constraint contains non-default information which may surpress the inheritance of incompatible information from other sources (i.e. the template TV). Thus, hjalpadi denotes the feature struture (where $I V$ is left unexpanded):

$$
\text { (22) }\left[\begin{array}{lll}
\text { val } & I V \\
\text { dir } & \text { right } \\
\arg \left[\begin{array}{ll}
\text { cat } & \text { np } \\
\text { struct } & - \\
\text { lex } & \text { dat } \\
\text { nom } & -
\end{array}\right]
\end{array}\right]
$$

Note also that vantar assigns lexical (i.e. nonstructural) accusative case to its subject.

The definitions above capture the intuitive difference between structural and lexical case. If a verb assigns structural, default case, only jts category needs to be specified, the relevant case constraints follow by inheritance. If a verb assigns lexical case, however, case must be specified explicitly. Although this analysis introduces a limited form of nonmonotonicity, this does not endanger the declarative nature of the grammar. The definitions in (21) still denote feature structures, and thus, the effect of combining default and non-default information can be computed at compile time. That is, there are no formal differences between a grammar using nonmonotonic inleritance and a grammar which does not. Furthermore, in Bouma (to appear) it is demonstrated that the inheritance operation itself can be defined declaratively. What is gained by using nonmonotonic inheritance is the fact that it supports a direct and natural implementation of certain linguistic observations.

\section{Case Preservation}

In this section $I$ argue that the case preservation phenomena which can be observed in raising and passive constructions are a reflection of a (partial) case agreement relation between two $\mathrm{NP}$-argument positions.
For raising to subject verbs, for instance, the case of controlling subject is always identical to the subject case constraint specified by the embedded VP (that is, $I$ assume that infinitival verbs may specify structural, nominative, case for their subject). Thus, raising to subject verbs can be defined as in (23). The paths 〈val ang and (arg arg) refer to the controlling and controlled NP, respectively.

$$
\begin{aligned}
& R-t o-S: \\
& (I V / V P \\
& \langle\text { val arg struct }\rangle=\langle\text { arg arg struct }\rangle \\
& \langle\text { val arg lex }\rangle=\langle\text { arg arg lex }\rangle \\
& \langle\text { val ary nom }\rangle=\langle\text { arg ary nom }\rangle) .
\end{aligned}
$$

The feature structures denoted by this template and by the templates defined below are shown in figure 1.

Raising to object verbs, on the other hand, do not take nominative objects and thus require that their object is [NOM -]. The other case features again agree:

$$
\begin{aligned}
& \text { R-to- } O: \\
& \left(\begin{array}{l}
(I V / N P) / V P \\
\\
\langle\text { val arg nom }\rangle=- \\
\langle\text { val arg struct }\rangle=(\text { arg arg struct }\rangle \\
\langle\text { val ary lex }\rangle=\langle\text { arg arg lex }\rangle
\end{array}\right) .
\end{aligned}
$$

Note that if the VP-complement assigns nominative case to its subject argunent, the object is specified as [STRUC1 +, NOM -]. This implies that the object must be accusative, as only the case template ACC will unify with this specification. In all other cases, the lexical case assigned by the $\mathrm{VI}^{\prime}$-complement will be preserved. In particular, a lexical accusative subject gives rise to the following derivation:

$$
\begin{aligned}
& \text { taliồ vanta peninga, } \\
& \text { [1] }\left[\begin{array}{lll}
\text { val } & \text { IV } \\
\text { dir } & \text { right } \\
\arg \left[\begin{array}{ll}
\text { cat } & \text { np } \\
\text { struct } & - \\
\text { lex } & \text { acc } \\
\text { nom } & -
\end{array}\right]
\end{array}\right]
\end{aligned}
$$

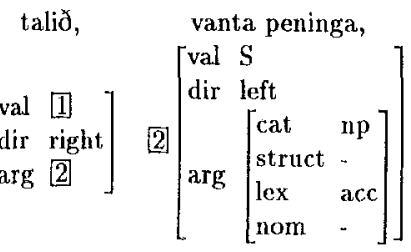




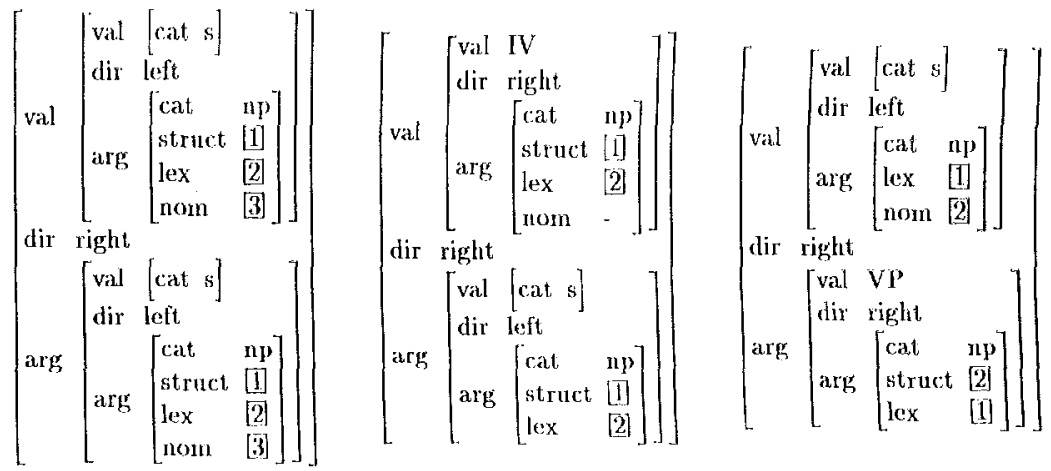

Figure 1: Feature structures for R-TO-S, R-'O-O, and PAss-Aux

Passive auxiliarics, finally, are delined as follows:

$$
\begin{aligned}
& (V P / T V P) \\
& \langle\text { val arg nom }\rangle=\text { (ary arg struct }\rangle \\
& \langle\text { val ary lex }\rangle=(\text { arg arg lex }\rangle \quad) \text {. }
\end{aligned}
$$

In passives, the question whether a nominative subject will appear or not is determined by the question whether the object of the TVP. complement receives structural case or not. If the object was marked for one of the lexical cases GEN or I A'T, this case will also appear on the subject. A structural accusative object gives rise to a $[\mathrm{NOM}+$, heX ACC] specification for the subject, which is unifiable with the case template Nom only. A lexical accusative object (as in (25)), on the other hand, gives rise to a [NOM -,LEX ACC] subject, a specification which is only unifiable with ACC. Note that this accounts for example (13), which showed that lexical accusative case must be preserved in passive constructions.

\section{Concluding Remarks}

In the previous sections I have argued that, contrary to what has been assumed in previous work, the Icelandic case system does not provide compelling evidence for the introduction of a nonmonotonic syntactic case component.

The same conclusion is reached by Sag $e t a l$. (to appear), who present an analysis formulated in terms of HPSG (Pollard \& Sag, 1987, to appear) which emphasizes the theoretical and methodological advantages of a declarative, lexicalist, solution. Their analysis rests on the assumption that case is encoded using the two features cAss and DCAsp, where the latter is used to concode the default case of certain argument positions. The distinction between structural and lexical case assigning verbs is implemented as follows:
Non-quirky verbs require that the DCASE and CASE values of their subjects be identified (structure-shared).
Quirky verbs impose no such identity, and select a particular c:AtE value for their subject.

It is assurued that raising verbs specify that the controlling and controlled $\mathrm{NP}$ are reentrant. Note that this predicts that the case of a lexjcal (quirky) case assigning verb is always preserved. If a rasing verb combines with a VPcomplement which assigns structural case to its subject, the features CAsE and DCASE of the controlling NP' will also be reentrant. Since objects are always (lexically) specified as [DCASE ACc], this implies that a raising to object verb which combines with it structural case assigning VP nust take an accusative case marked object. Subjects are assumed to be marked as [BCAsli, NOM] by the syntax rule which intro duces subjects. 'Thus, raising to subject verbs that combine with a structural case assigning VP can only take a nominative subject.

The fact that the case of subjects is determined at least in part by syntax is surprising, given the lexicalist approach advocated by Sag 
et al. It is essential for their analysis, however, that subjects of infinitives are not assigned nominative default case in the lexicon, as this would make it impossible for a raising to object verb to combine with its VP-complement ${ }^{6}$. In the account above, there was no need to introduce syntactic case marking principles. One might even maintain that this account, apart from being truly lexical, also has the advantage that it avoids the procedural flavor of the analysis of Sag et al, which, although formulated declaratively, makes essential use of the fact that nominative default case is imposed during syntactic processing, whereas all other case constraints are imposed beforehand (i.e. in the lexicon).

Sag et al. (to appear) do not adress the case marking patterns of passives. The most obvious way in which their analysis could cover these facts would be to assume the passive lexical rule presented in Pollard \& Sag (1987, p. 215). This seems to account for the facts immediately, given the additional assumption that objects are marked as [DCASE ACC] afler passive has applied. Note, however, that this would imply a slightly different lexical component than is standardly assumed in HPSG, and, perhaps more disturbing, would introduce explicit ordering of lexical rules or rule types.

\section{References}

Andrews, Avery (1982). The Representation of Case in Modern Icelandic. In J. Bresnan (ed.) The Mental Representation of Grammatical Relations, MIT Press, Cambridge, Mass., pp. 427503.

Bach, Emmon (1979). Control in Montague Grammar. Linguistic Inquiry 10, pp. 515-532.

Bach, Emmon (1980). In Defense of Passive. Linguistics \& Philosophy 3, pp. 297-341.

Bouma, Gosse (1988). Modifiers and Specifiers in Categorial Unification Grammar. Linguistics

\footnotetext{
${ }^{6}$ One might suggest that it is actually the morphological rule which creates finite verbs that imposes the constraint [DCASE NOM] on subject arguments. However, this would leave a sentence such as (i), mentioned by Sag et al. as evidence for the claim that nominative is assigned syntactically, unaccounted for. Note also that this example is unproblematic for the system presented above, given the assumption that vinoist selects an infinitival $S$.

(i) Mér(D) viröist hun(N) elska hamn(A)

me seems she to-love him
}

26, pp. 21-46.

Bouma, Gosse (to appear). Feature Structures and Nonmonotonicity. Groningen University. Comptational Linguistics 18.

Jacobson, Pauline (1990). Raising as Function Composition. Linguistics 8 Philosophy 13, pp. 423-476.

Karttunen, Lauri (1989). Radical Lexicalism. In M. Baltin \& A. Kroch (eds.) Alterative Conceptions of Phrase Structure, Chicago University Press, Chicago, pp. 43-66.

Pollard, Carl \& Ivan Sag (1987). InformationBased Syntax and Semantics, vol I: Fundamentals, CSLI Lecture Notes 13, University of Chicago Press, Chicago.

Pollard, Carl \& Ivan Sag (to appear). Information-Based Syntax and Semantics, vol II: Agrement, Binding, and Control, CSLI Lecture Notes, University of Chicago Press, Chicago.

Sag, Ivan, Lauri Karttunen, \& Jeffrey Goldberg (to appear). A Lexical Analysis of Icelandic Case. In I. Sig \& A. Szabolcsi (eds.), Lexical Matters, CSII Lecture Notes, Univerity of Chicago Press, Chicago.

Shieber, Stuart (1986a). An Introduction to Unification-Based Approaches to Grammar, CSII Lecture Notes \&, University of Chicago Press, Chicago.

Shieber, Stuart (1.986b). A Simple reconstrucion of GPSG . Proceedings of Coling 1986, Institut für angewandte Kommunikantions- und Sprachforschung, Bonn, pp. 211-215.

Uskoreit, Hans (1986). Categorial Unification Grammar. Proceedings of Coling 1986, Institut für angewandte Kommunikantions- und Sprachforschung, Bonn, pp. 187-194.

Yip, Moira, Joan Maling, \& Ray Jackendoff (1987). Case in Tiers. Language 63, pp. 217250.

Zaenen, Anuie, Joan Maling, \& Höskuldur Thráinsson (1985). Case and Grammatical Functions: The Icelandic Passive. Natural Language \& Linguistic Theory 3, pp. 441-484.

Zeevat, Henk (1988). Combining Categorial Grammar and Unification. In Uwe Reyle \& Christian Rohrer (eds.) Natural Language Parsing and Linguistic Theories, Reidel, Dordrecht, pp. 202-229. 